\title{
Head Morphology and Degree of Variation in Lacerta bilineata, Podarcis muralis and Podarcis sicula
}

\author{
Morfología de la Cabeza y el Grado de Variación en \\ Lacerta bilineata, Podarcis muralis y Podarcis sicula
}

${ }^{*, * *}$ Emiliano Bruner \& *David Costantini

BRUNER, E. \& COSTANTINI, D. Head morphology and degree of variation in Lacerta bilineata, Podarcis muralis and Podarcis sicula. Int. J. Morphol., 27(3):667-676, 2009.

SUMMARY: The morphology of cephalic scales in Lacertids is organised in well defined geometrical structures. The variation of these elements is related to the underlying bone growth and morphogenesis, but it is also associated with the muscular system and the sutural dynamics. In this paper, the patterns of variation of the cephalic scales have been compared between three common Mediterranean species: Podarcis muralis, Podarcis sicula and Lacerta bilineata. The morphospace generated by the morphological relationships within the cephalic system in these three species is investigated in order to consider their degree of variation and their anatomical peculiarities. Generally, Lacerta is 64\% larger than Podarcis, shows a relative reduction of the frontal scale, enlarged fronto-parietal structures, and stretched occipital area. L. bilineata shows the smaller degree of variation within the shape space, while $P$. muralis shows the highest values. The morphology of the two genera is definitely different mostly because of allometric variation. Non-allometric distinctions between the three species are subtle but detectable. The degree and pattern of variation are interpreted in terms of possible environmental pressures and of functional cranial dynamics associated with the fronto-parietal suture, respectively. In this sense, the structural relationships between bones and scales are of particular interest to further investigate ontogeny and phylogeny in reptiles.

KEY WORDS: Lacertids; Head morphology; Geometric morphometrics; Morphospace; Fronto-parietal suture.

\section{INTRODUCTION}

In vertebrates, a large part of the morphological differences are associated with size-related changes due to variations in rates or timing of growth and developmental processes (Gould, 1977; Shea, 1992; Klingenberg, 1998). Some allometric traits can be fitness-related (i.e., they can be intended as actual evolutionary adaptations), while others can be neutral consequences of rearrangements of the functional and structural organisation when scaled at different size. Recent studies on lizards have described allometric patterns of skull (Monteiro \& Abe, 1997; Barahona \& Barbadillo, 1998) or of cephalic scales (Bruner et al., 2005; Bruner \& Costantini 2007; Kaliontzopoulou et al., 2007; 2008). All these reports describe a differential allometric rate along the cephalic axis, mainly associated with an antero-posterior growth gradient. In terms of anatomy, such patterns of variation are supposed to be influenced by the growth and development of the cranial bones. The fronto-parietal suture, which is positioned under the frontoparietal scales, has been hypothesised to be a major pace-maker of the head elongation (Bruner \& Costantini). Diet and mating can also have a role in shaping the cephalic scales, through the muscles (jaw adductors and nuchal attachments) associated with feeding, coupling, or fighting (Bruner et al.).

The Italian lacertid fauna is mainly characterised by the following three species (Corti \& Lo Cascio, 1999): the common wall lizard Podarcis muralis, the Italian wall lizard Podarcis sicula and the western green lizard Lacerta bilineata. In this paper, we compare the cephalic morphology of these three Mediterranean species, analysed separately in previous studies, in order to generate a common multivariate space able to describe these taxa in terms of degree of variation and position along the patterns of covariance.

\footnotetext{
* Ornis italica, Piazza Crati 15, 00199 Roma, Italy and Centro Nacional de Investigación sobre la Evolución Humana, Burgos, Spain.
}

** Division of Ecology and Evolutionary Biology, Faculty of Biomedical and Life Sciences, University of Glasgow. 
The structure of the morphological space (morphospace, or shape space when dealing only with the shape differences) is related to the magnitude of withinsample variation and to the relationships between the anatomical elements. Hence, such multivariate space supplies a synthetic view of overall morphological differences within a framework generated by the rules underlying the spatial organisation of the anatomical system. Apart from the classic use of these procedures (i.e., to describe the patterns of covariation generating the final phenotypes and the departures from such trajectories), the analysis of the morphospace can also provide information on the level of organisation of the overall anatomical unit: the degree of variability and the modularity of the system.

The aim of the present analysis is to investigate the differences between these three species in terms of patterns and degree of variation, providing inferences on the factors involved in the regulation of their phenotypes in terms of structural and functional relationships. These factors are supposed to be directly related to the species-specific evolutionary and ecological frameworks.

\section{MATERIAL AND METHOD}

The sample includes specimens collected as prey remains from nest-boxes of Eurasian kestrels Falco tinnunculus (Costantini et al., 2005, 2007) and specimens directly photographed in the field by capture-release. Prey remains were used only when the preservation was sufficient enough to investigate head morphology and recognise the species.
All the individuals were recovered around Rome between 1999 and 2005 .

These species, (mostly the Genus Podarcis, and in particular Podarcis muralis) are recognised to present a very large variability, involving taxonomical problems (Corti \& Lo Cascio, 1999). However, the information available on this issue is only restricted to body size and to the chromatic patterns. Also, such recognised variability is not only associated with inter-population variation, but also with intrapopulational one. Hence, although our sample comes from a single geographic location, the problem of geographical variability seems to be not easily resolved by a different source of specimens. Also, this study is interested in the patterns of covariation more than to the variation per se. Therefore, supposing that the species-specific geographical variability is anyway expressed onto the same model of biological organisation, the specific geographical origin of our sample should not bias the analysis of the correlation between traits. This is even more reasonable taking into account that the specimens of all the three species have the same geographical provenience, being the environmental variation only related to the species-specific microclimatic differences.

Every species was represented by 40 individuals (sexes are pooled). The cephalic area of each specimen was photographed in dorsal view, and the images were used to sample a bilateral configuration of 14 bidimensional landmarks localised at the boundaries of frontal, frontoparietal, interparietal, and occipital scales (Fig. 1; see Bruner et al.; Bruner \& Costantini (2007) for further details). Coordinates were sampled using tpsDig 1.20 (Rohlf, 1998).

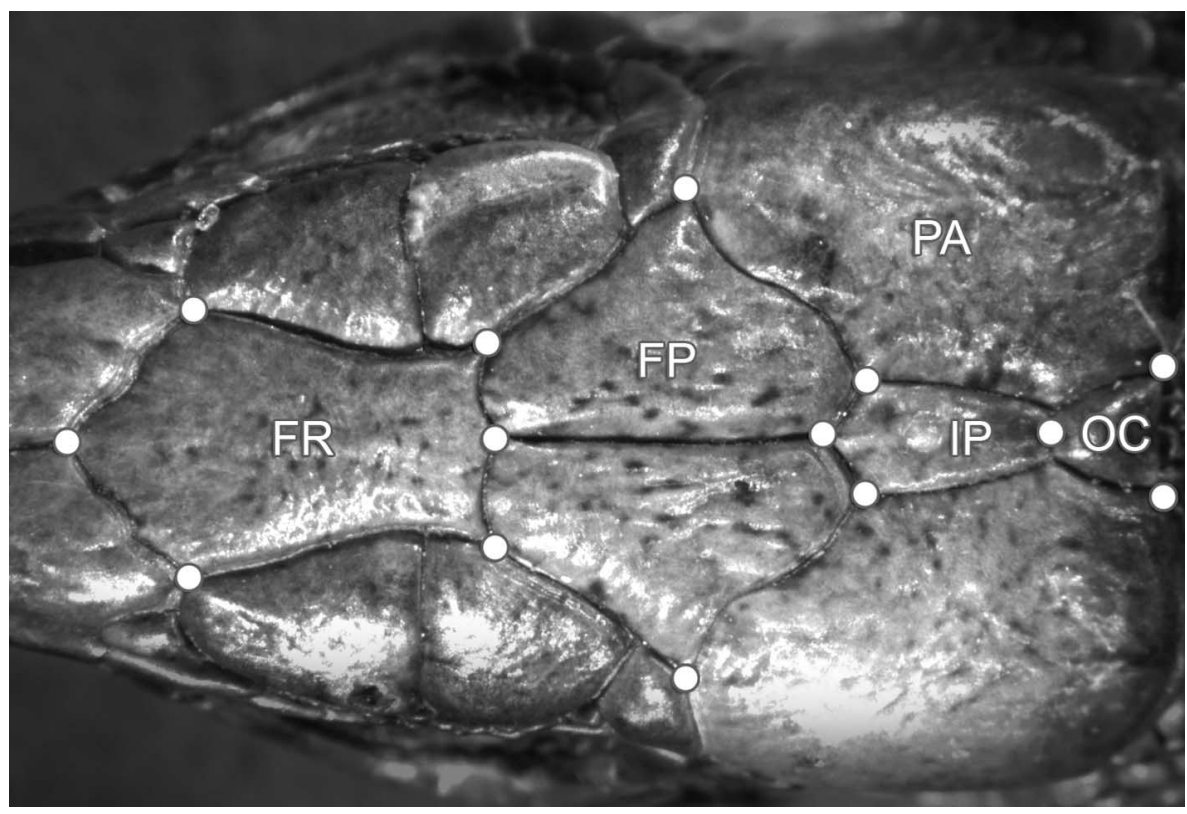

Fig. 1. The analysis has been computed using a bilateral 2D configuration with 14 landmarks, localising the boundaries of the frontal (FR), fronto-parietal (FP), parietal (PA), interparietal (IP), and occipital (OC) scales. 
The shape space was investigated through geometric morphometrics (Zelditch et al., 2004). The coordinates were superimposed through a Procrustes approach and the differences were analysed by using multivariate ordination techniques (Bookstein, 1991). Generalised Procrustes Analysis (GPA) compares the configurations after translation to a common centroid, scaling to unitary centroid size, and rotation in order to minimise the differences between corresponding landmarks through a least-square procedure. In shape analysis, the covariation between the residuals within the sample is used to perform multivariate ordinations able to localise vectors (i.e., linear combination of the variables) explaining the structure of the morphological variability. Shape variation was analysed by Principal Component Analysis (PCA) and Canonical Variates Analysis (CVA). The degree of variation within the shape space for each species was quantified using the species-specific standard deviation on each PCA axis. The relationship between shape and centroid size was tested by univariate regression on the principal components, multivariate regression on the whole shape variables through partial least square approach, and regression of the centroid size onto the shape residuals, both in the pooled sample and separating the two genera. This last approach computes the regression of the size and shape deviations of each specimen from the respective group-specific mean (pooled within-group regression; Klingenberg, 2008). The covariation between size and shape is then computed according to the residuals of each specimen relatively to the average values of its group. This approach is necessary mostly when dealing with taxa that differ in size, as in the present study in which L. bilineata is definitely larger than the two Podarcis species (see below). Geometric morphometric was performed through symmetrised bilateral configurations using MorphoJ 1.00 (Klingenberg, 2008). Partial Least Square regression was computed with tpsPLS 1.18 (Rohlf, 2006).

Because of the discrete separation between the two genera within the shape space (see Results), a further analysis was computed pooling the two Podarcis species and providing a direct (pairwise) comparison between the two groups also through Euclidean Distance Matrix Analysis (EDMA; Richstmeier et al., 2002). EDMA compares the average forms through computing the ratio of every possible interlandmark distance, and considering the $95 \%$ confidence intervals for each diameter. L. bilineata was used as numerator, and, consequently, for each interlandmark distance the respective value represents the ratio between the L. bilineata figure and the Podarcis figure. EDMA was performed using WinEdma (Cole, 2002). Because of the superimposition-free approach of this method, the comparison was computed using a unilateral configuration (right side). Univariate and bivariate statistics were computed with PAST 1.81 (Hammer et al., 2001).

\section{RESULTS}

Shape space. A Principal Component Analysis shows that the morphospace is characterised by a dominant first axis, with successive components smoothly and gradually decreasing the explained variance. Hence, there is no steep point of curvature along the resulting scree plot, suggesting a homogeneous distribution of the whole variability through the shape space (Figs. 2a,b). Although $95 \%$ of the whole variation is expressed in the first 9 components, only the first 4 principal axes explain more than $5 \%$ each. This value is often used as rule of thumb conventional threshold to discard minor components possibly associated more with noise than with useful statistical signal. Considering these first four morphological vectors, $P$. muralis is 1.43 times more variable than $P$. sicula, and 1.99 times more variable than L. bilineata (Figs. 2c,d). The larger variation in Podarcis is related to the first three components, and largely associated with the second one for $P$. muralis. L. bilineata shows a similar degree of variation between these four axes, while the other two species display different values for each component.

The first two components account for $57 \%$ of the variance (Fig. 3). The first component (38\%) separates $L$. bilineata from both Podarcis species $(\mathrm{P}<0.001)$, and is associated with a relatively shorter frontal, longer frontoparietal scales, anterior enlargement of the intraparietal area, and posterior stretching of the occipital scale in the former group. The second component (19\%) further separates the two genera $(\mathrm{P}<0.001)$. PC2 is associated with a frontoparietal widening and an anterior enlargement of the interparietal scale in L. bilineata.

A Canonical Variates Analysis succeeds in separating the three species (Fig. 4). The first discrimination axis separates the two genera through a vector similar to the first principal component. Actually, this axis and the first component of variation are largely correlated $(\mathrm{R}=0.82)$. The second axis separates $P$. muralis and $P$. sicula, by means (in the latter) of a reduction of occipital and interpariatal scales and a relative enlargement of the frontoparietal area.

Allometry. The centroid size is larger in L. bilineata $(\mathrm{P}<$ 0.001). According to the partial least square regression, size accounts for $77 \%$ of the shape variation within the present sample $(\mathrm{R}=0.88, \mathrm{P}=0.001)$. A multiple regression between the centroid size and the first four shape components gives a similar result $\left(\mathrm{R}_{\text {adj }}^{2}=0.78, \mathrm{P}<0.001\right)$. The allometric vector computed by PLS approach or by using the pooled residuals is definitely similar to the first principal components, being PC1 and centroid size markedly correlated $(\mathrm{R}=0.86 ; \mathrm{P}<$ 


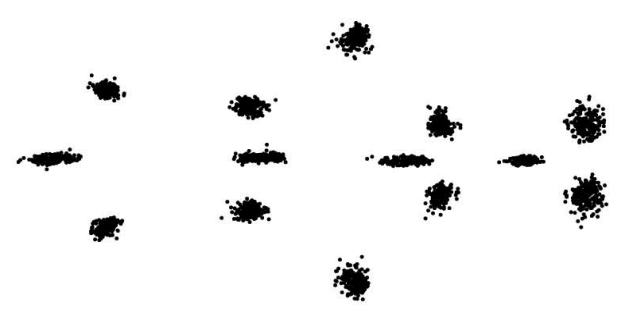

a

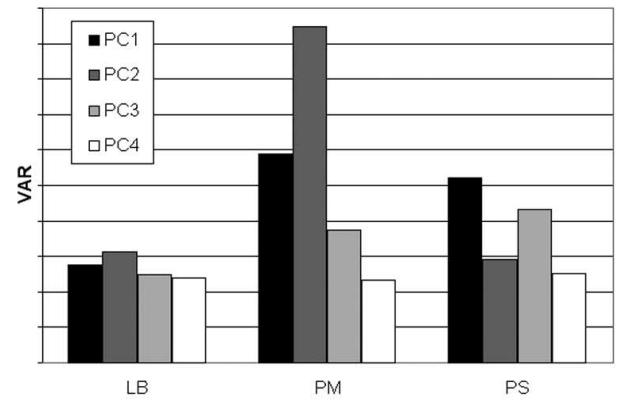

C

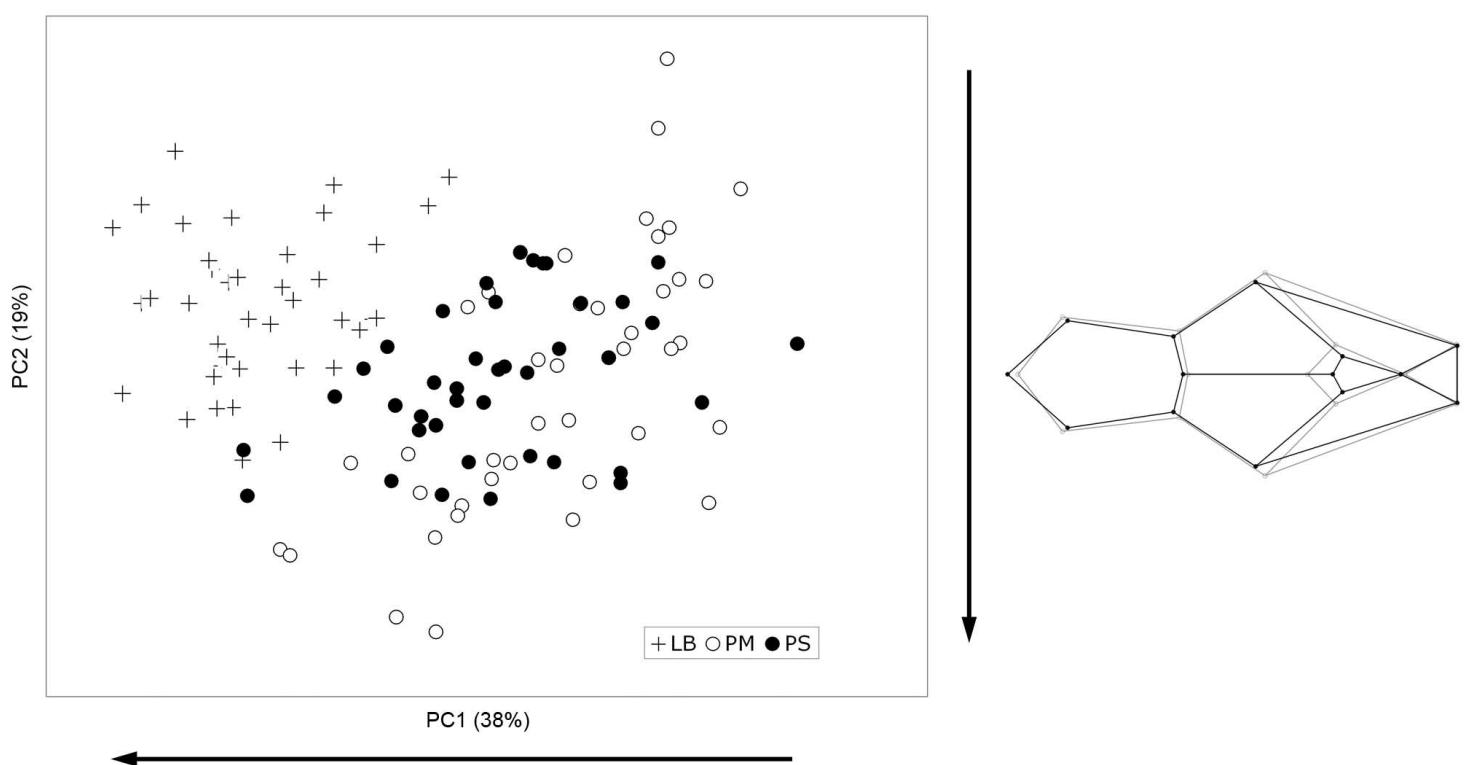

Fig. 2. a) Scatter plot of the whole sample after Procrustes superimposition; b) scree plot of the Principal Component Analysis, showing the single $(\%)$ and cumulative (CUM) variance for the first ten components; c): variation (as standard deviation) in L. bilineata (LB), P. muralis (PM), and P. sicula (PS) for the first four components; d) cumulative variation in each species for the first four components.

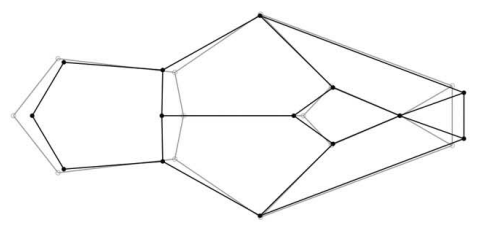

Fig. 3. First and second principal components, and distribution of the three species (LB: L. bilineata; PM: P. muralis; PS: P. sicula). Wireframes show the geometrical patterns associated with the two covariation axes. 

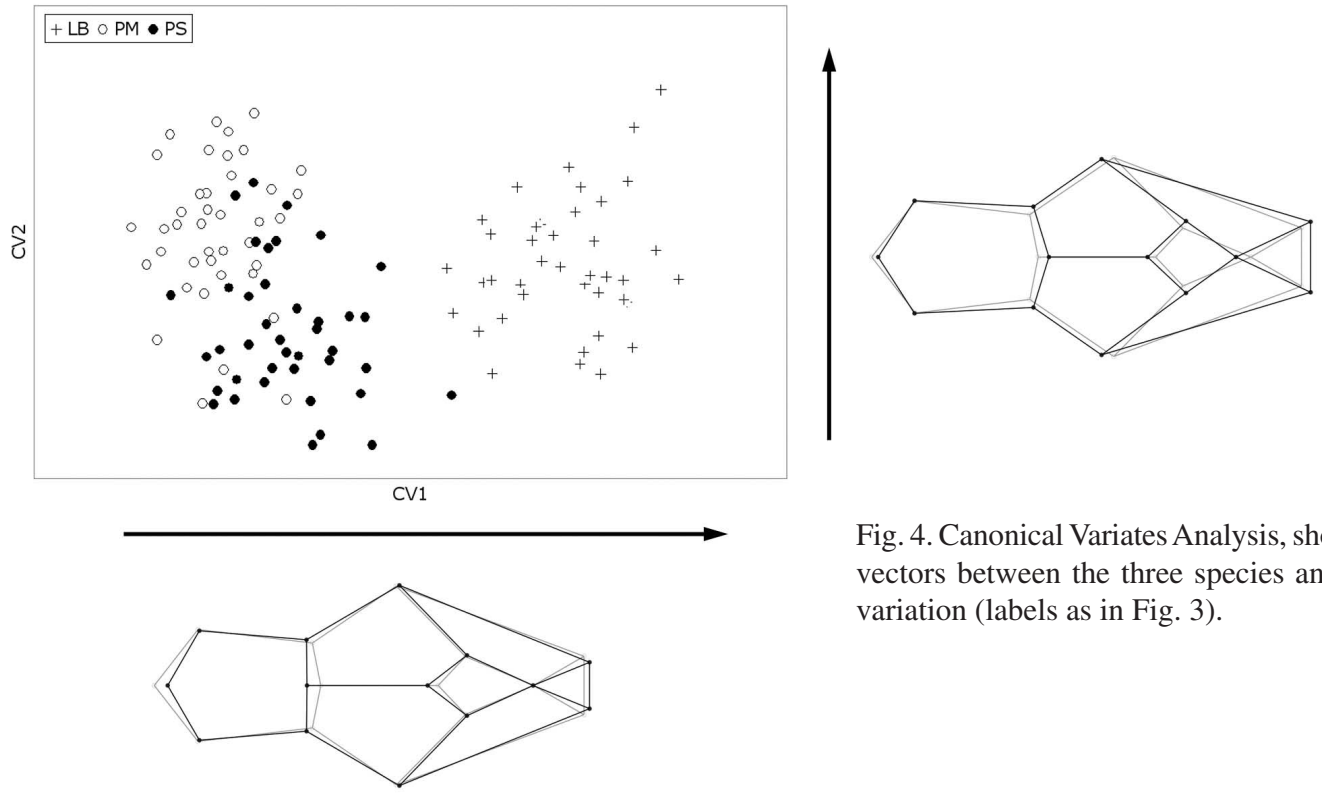

Fig. 4. Canonical Variates Analysis, showing the two discrimination vectors between the three species and the associated patterns of variation (labels as in Fig. 3).
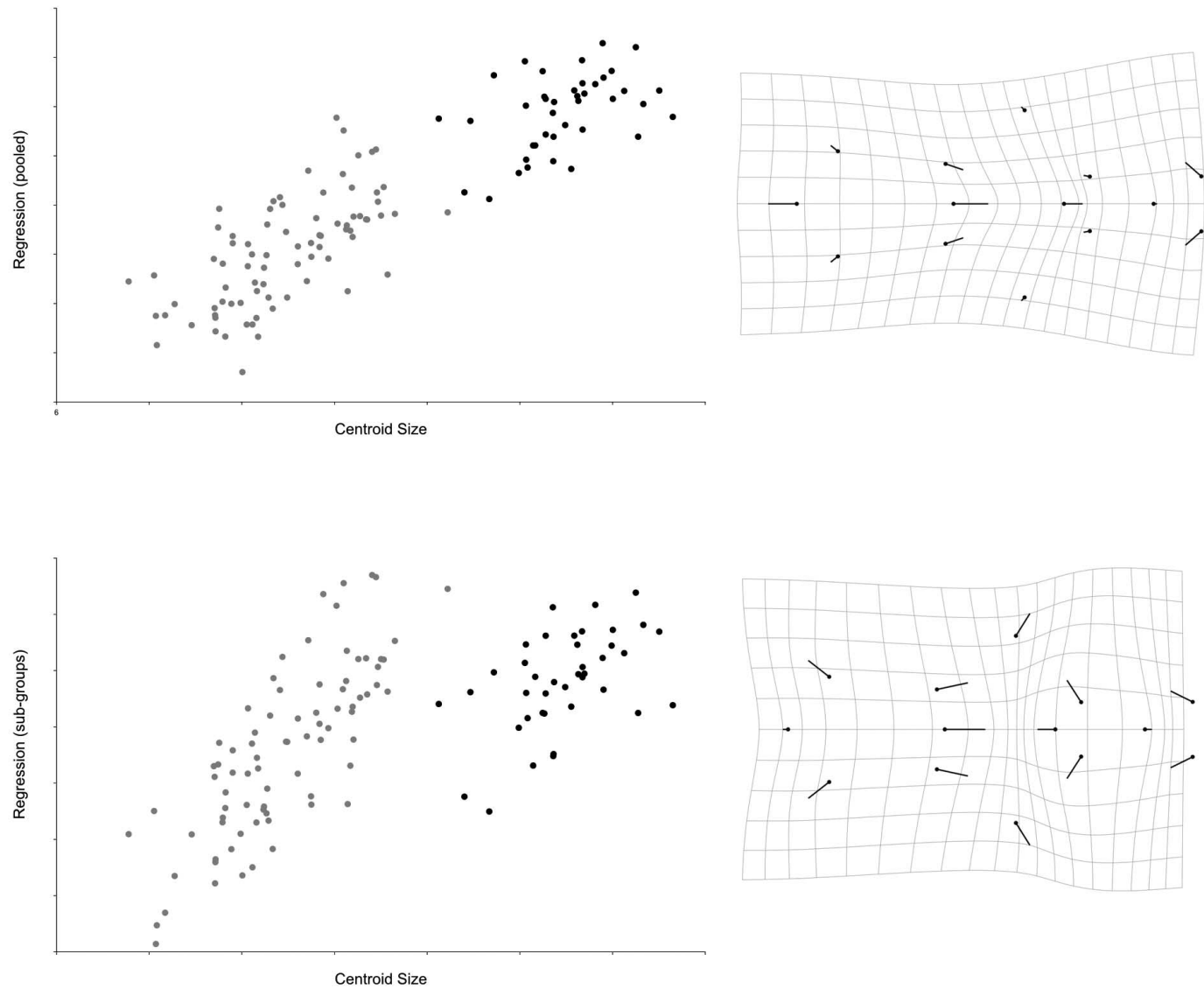

Fig. 5. Regression between centroid size and shape variation by using the whole sample (upper plot) and the within-genus variation (lower plot) for Podarcis (pooled species, grey dots) and L. bilineata (black dots). The thin-plate spline deformation grids show the two allometric patterns, from larger to smaller sizes. 
0.001) (Fig. 5a). No other principal components present a significant correlation with size. Along this allometric pattern, the distribution of the two Podarcis species largely overlaps, while the distribution of L. bilineata is discretely separated by means of its larger size. The trajectories of the two genera seem to show some minor differences in their parameters, but such differences are not significant when the $95 \%$ confidence intervals are computed for their major axes. In fact, the estimates of both slopes and intercepts largely overlap. Furthermore, an analysis of covariance fails to report significant differences in the shape between the two groups when size is taken into account as a covariate. The Podarcis group shows a stronger correlation between size and shape changes $(\mathrm{R}=0.66, \mathrm{P}<0.001)$ than $L$. bilineata $(\mathrm{R}=0.44, \mathrm{P}=0.005)$.

If the first principal component is eliminated by using a multivariate projection (Burnaby's removal), a successive discrimination analysis fails to recognise significant residual differences between the two groups $(\mathrm{P}=0.10)$.

When the regression is computed on the groupspecific variation, the two genera show similar shape changes but scaled at the genus-specific size range (Fig. 5b). While the general allometric vector is only correlated with PC1, this pooled-within group vector is correlated both with $\mathrm{PC} 1$ $(\mathrm{R}=0.80, \mathrm{P}<0.001)$ and $\mathrm{PC} 2(\mathrm{R}=0.59, \mathrm{P}<0.001)$. Being a combination of the first two principal components, the morphological variation associated with this second allometric pattern is different from the previous (pooled) one, mostly because of the opposite movement of the anterior boundary of the interparietal scale. This variation generates from larger to smaller figures a geometrical compression in the middle of the frontoparietal scale.

It is worth noting that if the pooled within-group regression is performed separating each species instead of the two genera the results are the same, both in terms of values and geometrical pattern (data not shown). This is someway expected, considering the overlap in both shape and size for the two Podarcis species.

Euclidean Distance Matrix Analysis. Considering that the two Podarcis species largely overlap within the shape space while L. bilineata is discretely separated by this group, a form pairwise comparison was computed between the two genera by using an EDMA approach to analyse the absolute (quantitative) differences between the two groups in terms of ratios for every interlandmark distance.

The analysis of the form difference matrix shows that L. bilineata has diameters ranging from $130 \%$ to $220 \%$ of those from the Podarcis species, with a median value of 164\% (Fig. $6)$. The diameters with values less than one standard deviation from this average (that is, those showing the lesser increase) are those related to the size of the frontal scale, while those exceeding one standard deviation (that is, those showing the larger increase) are associated with the size of the frontoparietal area and lengthening of interparietal and occipital scales.

The anterior border of the interparietal scale is an outlier of this distribution, showing a value of 2.20. This means that $L$. bilineata displays an average value as much as $120 \%$ larger than the Podarcis figure.

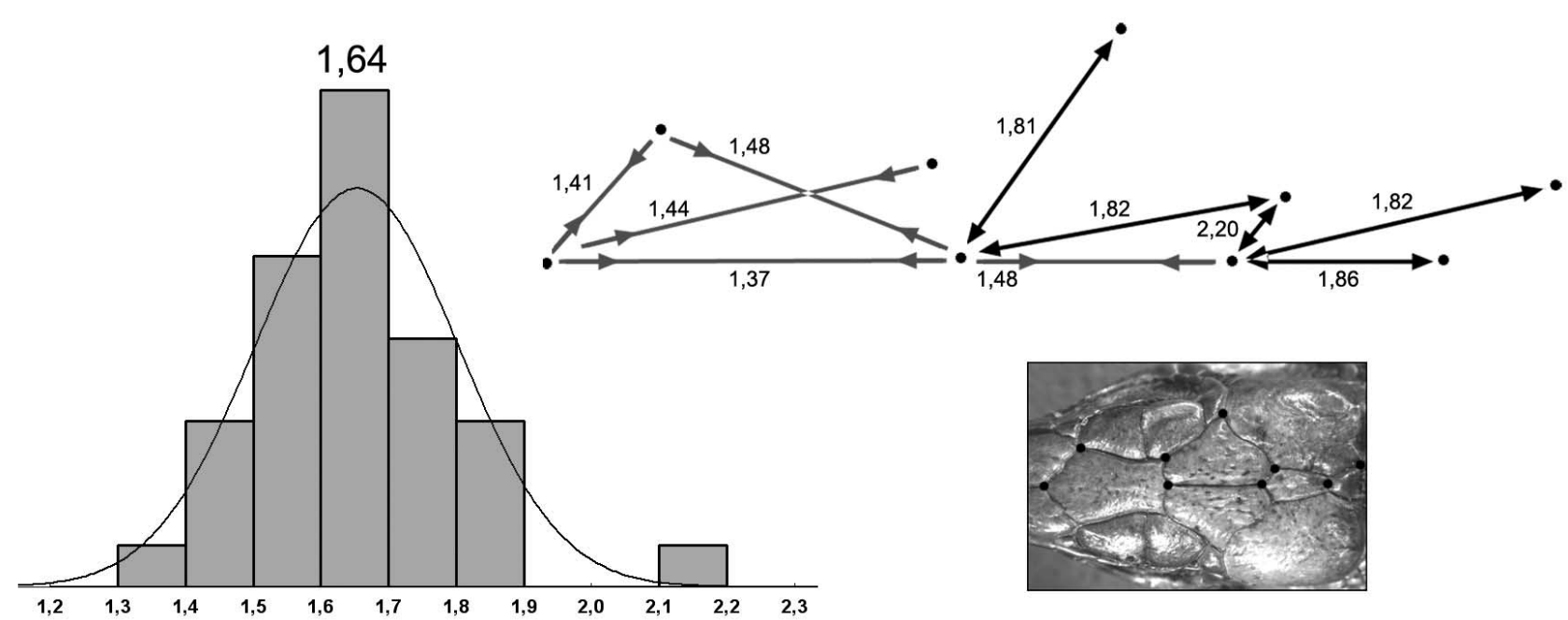

Fig. 6. Euclidean Distance Matrix Analysis on the hemiconfiguration between Lacerta and Podarcis. The histogram shows the distribution of the values from the Form Difference Matrix (FDM) computed using Lacerta bilineata as numerator, showing a median increase of $64 \%$, with a general range spanning from $130 \%$ (ratio 1.3) to $220 \%$ (ratio 2.2). The upper diagram shows the diameters from the FDM with values larger (black) and lower (grey) than one standard deviation (i.e., lengthening much more or much less than the average increase) onto the right hemiconfiguration, with their respective ratios. 


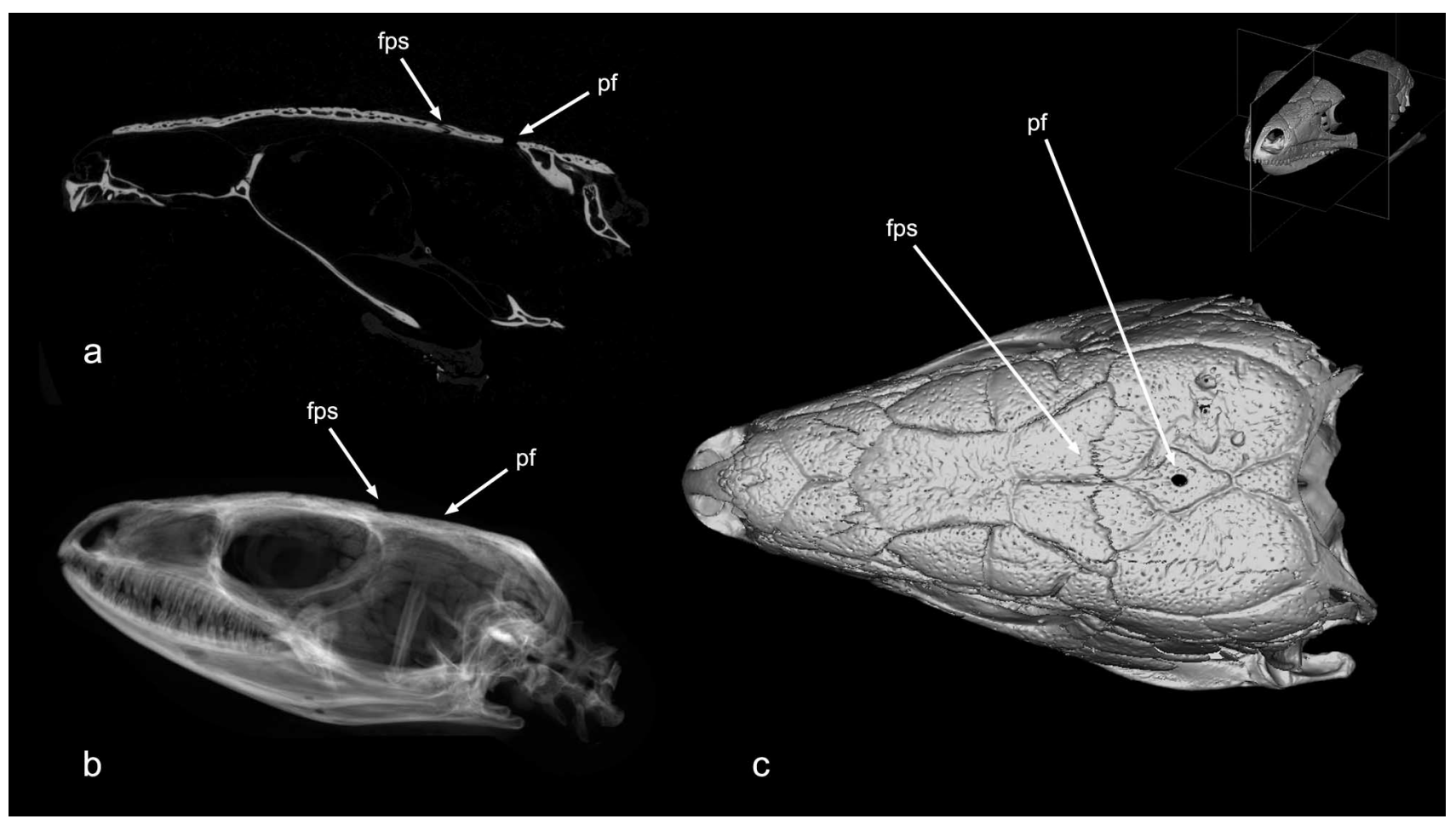

Fig. 7. Microtomographic sections and reconstruction of the green lizard skull. The position of the parietal (pineal) foramen (pf), and of the frontoparietal suture (fps) are shown on a sagittal slice (a), on a densitometric lateral projection (b), and on a 3D reconstruction of the skull in upper view (c). The imprints of the scales are easily recognisable on the 3D surface rendering (isometric voxel size: $36 \mu \mathrm{m}$ ).

\section{DISCUSSION}

The anatomy of cephalic scales of lizards displays a clear geometrical organisation, which is easily investigated through landmark-based morphometrics. In the present analysis, we described the morphological variations, similarities and differences between the most representative lacertid species of the Italian peninsula, belonging to the genera Lacerta and Podarcis.

These two genera are discretely separated by virtue of size differences, being the green lizard in average $64 \%$ larger than the Podarcis group. The dimensional differences between the two genera are not homogeneous, increasing from the anterior areas (35-50\% larger in Lacerta) to the posterior ones $(80-90 \%)$. An outstanding difference is represented by the length of the anterior border of the interparietal scale, averaging in the green lizard 2.2 times the figure of the small species.

The morphospace generated by the covariations within this sample is not particularly polarised along a few and well-separated principal components. Generally, the more a morphological system is integrated, the more the multivariate space is characterised by few dominant vectors
(Wagner, 1984). In this case, we may, therefore, suggest that the head scale variation, although characterised by some factors organising the gross spatial relationships, does not show a very strict regulation of the evolutionary morphological patterns through marked functional constraints.

Size related differences account for a large part of the shape variation $(77 \%)$, including two sources of allometric changes: interspecific absolute variations (characterising the first morphological component) and intraspecific relative variations (characterising the first two morphological components).

These two kinds of variation (intra and inter-specific) require different statistical models and different biological interpretations (Martin \& Barbour, 1989), and their joint analysis in a multivariate approach may generate mixed perspectives (Mitteroecker et al., 2004). In a multivariate context, an intra-specific covariation pattern is supposed to be the result of a true biological factor creating functional and structural relationships between the anatomical elements. On the other hand, a vector associated with inter-specific 
variation may not be necessarily related to a real biological trajectory, being influenced by species-specific adaptations and discontinuities. Hence, a joint analysis will produce a rotation of the resulting multivariate space influenced by both Gaussian random variations (i.e., intra-specific components) and non-normal distributions associated with adaptive changes (i.e., inter-specific components). When these two sources of variability are not undeniably organised along the same axes of covariation, the resulting space projection must be properly interpreted. In the present analysis, the first principal component and the general allometric vector should be intended as a general trend more than an actual biological signal, being a multivariate projection of two sources of variation. As a matter of fact, the overall geometric pattern computed on the whole sample, although strongly discriminant and definitely organising the morphospace, is different from those measured for the two groups, separately (Bruner et al.; Bruner \& Costantini). On the other hand, the pooled within-group regression (a combination of the first two components of shape) gives a morphological pattern definitely comparable to that described for each group, which must be assumed to represent a true biological component. Such pattern is shared by the three species, with similar shape changes at different size (i.e., larger for L. bilineata).

When the allometric component is eliminated, residual differences are hard to detect. This is also due to the different magnitude of these general allometric constraints, being the morphological variation in L. bilineata less strongly correlated to size. However, the most striking difference between the general and groups-specific allometric patterns is the behaviour of the anterior interparietal landmark. The same trait (anterior enlargement of the interparietal scale in L. bilineata) represents the most exceptional difference when the two forms of the two genera are compared. This feature is not actually associated with any of the true allometric schemes detected in Podarcis or Lacerta. Hence, it may be supposed to be a size independent trait of L. bilineata. The interparietal scale covers the parietal foramen, associated with the underlying pineal system (Fig. 7). The parietal eye includes lens, retina, and other photoreceptive structures, related to the hormonal activity of the pineal gland. Interestingly, although detailed information on this anatomical trait is incredibly scarce, L. bilineata also shows long pineal extensions when compared with other lacertid species, such as $P$. muralis (Gundy \& Wurst, 1976). Hence, it should be tested whether or not the non-allometric enlargement of the interparietal scale in L. bilineata is associated with its peculiar pineal anatomy.

Concerning the true shared allometric trend, we have already suggested how these morphogenetic patterns could be particularly influenced by both soft and hard tissues, the former through the relationships between scales and the underlying muscular masses (Bruner et al.), the latter by means of the dynamics of fronto-parietal suture (Bruner \& Costantini). Such suture is a relevant modulator of the lizard skull morphogenesis and kinesis (Barahona \& Barbadillo). In this sense, the structural and functional relationships between bones and scales are particularly informative and can provide very relevant cues on the cranial dynamics in lizards (see Fig. 7).

All these notes are mainly aimed at comparing the similarities and differences between L. bilineata and the two Podarcis species, taking into account the large morphological affinity between the two small-sized lizards. Nonetheless, although $P$. muralis and $P$. sicula basically share also a similar allometric pattern, $P$. sicula shows relatively larger frontoparietal scales and a reduction of the occipital area (Bruner \& Costantini). The current discrimination analysis, including the variation of L. bilineata, supports our previous findings.

A final note concerns the degree of variation. $L$. bilineata is the most homogeneous and, at the same time, the less variable species. On the other hand, P. muralis shows the largest degree of phenotypic variation and heterogeneity along the morphological vectors, mostly on those axes associated with the allometric changes. Such differences in species distribution within the morphospace should be interpreted in terms of both phenotypic plasticity and strength of the allometric component. The phenotypic plasticity accounts for the overall variation (i.e., the range of dispersion of the taxon within the multivariate space), while the strength of the allometric component mirrors the homogeneity of distribution (i.e., the direction of the dispersion within the morphospace). Concerning variation, $P$. muralis has been already supposed to display a marked phenotypic plasticity (Oliverio et al., 2000). Concerning homogeneity, L. bilineata seems to display smaller allometric constraints, as quantified by the differences in correlation coefficients between size and shape.

If the present sample sufficiently represents the actual species-specific variation, we should interpret these differences in terms of genetics (selection) or physiology (environmental response). The smaller variation in $L$. bilineata can be associated with factors influenced by its larger size, such as metabolic or biomechanical constraints. The differences between the two Podarcis species are more interesting because the two species have a similar body size. Although generally overlapping in terms of gross geographical distribution and body size, P. muralis and P. sicula present some definite ecological and evolutionary differences that seem to make them not sister species (Capula 
et al., 1993; Corti \& Lo Cascio; Oliverio et al., 1998, 2000; Harris et al., 2005; Arnold et al., 2007). As far as ecology, $P$. sicula is much more ground-dwelling than $P$. muralis. Also, a study carried out in the same geographic area of the of the present study shows that $P$. muralis is more generalist than $P$. sicula in terms of microhabitat preferences (Capula et al.). Moreover, the population density of $P$. muralis is higher than that of $P$. sicula in humid places with thick vegetation, while $P$. sicula is more abundant in sunny dry places (Capula $e t$ $a l$.). Size is a limiting factor for arboreal locomotion, and the larger variation in $P$. muralis mostly toward the lower ranges of the size distribution may be related to this more generalised environment. A wider range in size (and consequently in shape) may be hence selected to exploit more different resources in terms of habitats, or may induce secondarily to the use of a wider environmental spectrum. $\mathrm{Be}$ it cause or consequence, it seems reasonable that the degree of variation and the ecological niche are related to each other by a number of factors, such as microclimate characteristics (temperature and humidity), diet, locomotion, and even the use of refugees for escaping predators (Andrews, 1982; Saint Sirons et al., 1989; Arnold et al.).
A further point warranting attention is the integration between geometry and biomechanics of the lizards' skull (Moazen et al., 2008). In terms of functional craniology (Moss \& Young, 1960), the most intriguing topic of next studies should be the structural relationships and biomechanical interactions between bones and scales, within the patterns of morphological integration associated with the cephalic evolutionary dynamics.

\section{ACKNOWLEDGEMENTS}

We are grateful to Christian Klingenberg, Andrea Cardini, and Merhan Moazen, for their comments and suggestions. The microtomographic analysis was performed at the Centro Nacional de Investigación sobre la Evolución Humana (Burgos), thanks to the collaboration with Maria Lapresa Alonso. This work is partially supported by Ornis italica. David Costantini dedicates this paper to the memory of his mother, Nadia Macciocchi.

BRUNER, E. \& COSTANTINI, D. Morfología de la cabeza y el grado de variación en Lacerta bilineata, Podarcis muralis y Podarcis sicula. Int. J. Morphol., 27(3):667-576, 2009.

RESUMEN: La morfología de las escamas cefálicas en Lacértidos se organiza en estructuras geométricas bien definidas. La variación de estos elementos está relacionada con el crecimiento y la morfogénesis del hueso subyacente, pero está también es asociada con el sistema muscular y sutural dinámico. En este trabajo, son comparados los patrones de variación de las escamas cefálicas de tres especies mediterráneas comunes: Podarcis muralis, Podarcis sicula y Lacerta bilineata. El morfoespacio generado por las relaciones morfológicas con el sistema cefálico en estas tres especies se investigó con el fin de examinar su grado de variación y sus peculiaridades anatómicas. En general, Lacerta es 64\% más grande que Podarcis, muestra una reducción relativa de la escama frontal, alargamiento de la estructura fronto-parietal, y estrechamiento del área occipital. L. bilineata muestra el menor grado de variación en la forma del espacio, mientras que $P$. muralis muestra los valores más altos. La morfología de los dos géneros es diferente principalmente debido a variaciones alométricas. Diferencias no alométricas entre las tres especies son sutiles pero detectables. El grado y el patrón de variación son interpretados en términos de las posibles presiones del medio ambiente y la dinámica funcional craneal asociada a la sutura fronto-parietal, respectivamente. En este sentido, las relaciones estructurales entre los huesos y las escamas son de particular interés para seguir investigando ontogenia y filogenia de los reptiles.

PALABRAS CLAVE: Lacertidos; Morfología de la cabeza; Morfometría geométrica; Morfoespacio; Sutura fronto-parietal.

\section{REFERENCES}

Andrews, R. M. Patterns of growth in reptiles. In: Gans, C. (Ed.), Biology of the Reptilia. London, Academic Press, 1982. pp. 273-320.

Arnold, E. N.; Arribas, O. \& Carranza, S. Systematics of the Palaearctic and Oriental lizard tribe Lacertini (Squamata: Lacertidae: Lacertinae), with descriptions of eight new genera. Zootaxa, 1430:1-86, 2007.

Barahona, F. \& Barbadillo, L. J. Inter- and intraspecific variation in the post-natal skull of some lacertid lizards. J. Zool., London 245:393-405, 1998.
Bookstein, F. L. Morphometrics tools for landmarks data: geometry and biology. Cambridge, Cambridge University Press, 1991.

Bruner, E. \& Costantini, D. Head morphological variation in Podarcis muralis and Podarcis sicula: a landmark-based approach. Amphibia-Reptilia, 28:566-73, 2007.

Bruner, E.; Costantini, D.; Fanfani, A. \& Dell'Omo, G. Morphological variation and sexual dimorphism of the cephalic scales in Lacerta bilineata. Acta Zool. 86:245-54, 2005. 
Capula, M.; Luiselli, L. \& Rugiero, L. Comparative ecology in sympatric Podarcis muralis and P. sicula (Reptilia: Lacertidae) from the historical centre of Rome: what about competition and niche segregation in an urban habitat? Boll. Zool., 60:287-91, 1993.

Cole, T. M. III. WinEDMA: Software for Euclidean distance matrix analysis. Version 1.0.1 beta. Kansas City: University of Missouri, Kansas City School of Medicine, 2002.

Corti, C. \& Lo Cascio, P. I. Lacertidi italiani. Palermo, L'Epos, 1999.

Costantini, D.; Casagrande, S.; Di Lieto, G.; Fanfani, A. \& Dell'Omo, G. Consistent differences in feeding habits between neighbouring breeding kestrels. Behaviour, 142:1409-21, 2005.

Costantini, D.; Bruner, E.; Fanfani, A. \& Dell'Omo, G. Male-biased predation of western green lizards by Eurasian kestrels. Naturwissenschaften, 94:1015-20, 2007.

Gould, S. J. Ontogeny and phylogeny. Cambridge, Harvard University Press, 1977.

Gundy, G. C. \& Wurst, G. Z. Parietal eye-pineal morphology in lizards and its physiological implications. Anat. Rec., 185:419-31, 1976.

Hammer, O.; Harper, D. A. T. \& Ryan, P. D. PAST: Paleontological statistics software package for education and data analysis. Palaeont. Electr., 4:1-9, 2001.

Harris, D. J.; Pinho, C.; Carretero, M. A.; Corti, C. \& Böhme, W. Determination of genetic diversity within the insular lizard Podarcis tiliguerta using mtDNA sequence data, with a reassessment of the phylogeny of Podarcis. Amphibia-Reptilia, 26:401-7, 2005.

Kaliontzopoulou, A.; Carretero, M. A. \& Llorente, G. A. Head shape allometry and proximate causes of head sexual dimorphism in Podarcis lizards: joining linear and geometric morphometrics. Biol. J. Linn. Soc., 93:111-24, 2008.

Kaliontzopoulou, A.; Carretero, M. A. \& Llorente, G. A. Multivariate and geometric morphometrics in the analysis of sexual dimorphism variation in Podarcis lizards. J. Morphol., 268:15265, 2007.

Klingenberg, C. P. Heterochrony and allometry: The analysis of evolutionary change in ontogeny. Biol. Rev. Camb. Philos., 73:79123, 1998.

Klingenberg, C. P. MorphoJ. Faculty of Life Sciences, University of Manchester, UK, 2008.

Martin, R. D. \& Barbour, A. D. Aspects of line-fitting in bivariate allometric analyses. Folia Primatol., 53:65-81, 1989.

Mitteroecker, P.; Gunz, P.; Bernhard, M.; Schaefer, K. \& Bookstein, F. L. Comparison of cranial ontogenetic trajectories among great apes and humans. J. Hum. Evol., 46:679-97, 2004.
Moazen, M.; Curtis, N.; Evans, S. E.; O’Higgins, P. \& Fagan, M. J. Rigid-body analysis of a lizard skull: Modelling the skull of Uromastyx hardwickii. J. Biom., 41:1274-80, 2008.

Monteiro, L. R. \& Abe, A. S. Allometry and morphological integration in the skull of Tupinambis merianae (Lacertilia: Teiidae). Amphibia-Reptilia, 18:397-405, 1997.

Moss, M. L. \& Young R. W. A functional approach to craniology. Amer. J. Phys., Anthropol., 18:281-92, 1960.

Oliverio, M.; Bologna, M. A. \& Mariottini, P. Molecular biogeography of the Mediterranean lizards Podarcis Wagler, 1830 and Teira Gray, 1838 (Reptilia, Lacertidae). J. Biog., 27:1403-20, 2000.

Oliverio, M.; Bologna, M. A.; Monciotti, A.; Annesi, F. \& Mariottini, P. Molecular phylogenetics of the Italian Podarcis lizards (Reptilia, Lacertidae). Ital. J. Zool., 65:315-24, 1998.

Richtsmeier, J. T., Deleon, V. B. \& Lele, S. R. The promise of geometric morphometrics. Yearbook Phys. Anthrop., 45:63-91, 2002.

Rohlf, F. J. tpsDig 1.20. Ecology and Evolution. NY, SUNY at Stony Brook, 1998.

Rohlf, F. J. tpsPLS 1.18. Ecology and Evolution. NY, SUNY at Stony Brook, 2006.

Saint Sirons, H.; Castanet, J.; Bradshaw, S. D. \& Baron, J. P. Démographie comparée de deux populations françaises de Lacerta viridis (Laurenti, 1768). Rev. Ecol. (Terre Vie), 44:36186, 1989.

Shea, B. T. Developmental perspective on size change and allometry in evolution. Evol. Anthrop., 1:125-34, 1992.

Wagner, G. P. On the eigenvalue distribution of genetic and phenotypic dispersion matrices: Evidence for a nonrandom organization of quantitative character variation. J. Math. Biol., 21:77-95, 1984.

Zelditch, M. L.; Swiderski, D. L.; Sheets, H. D. \& Fink, W. L. Geometric morphometrics for biologists. San Diego, Elsevier, 2004.

\section{Correspondence to:}

Division of Ecology and Evolutionary Biology

Faculty of Biomedical and Life Sciences

University of Glasgow

Graham Kerr Building, room 511

Glasgow G12 8QQ

UK

Email: d.costantini@bio.gla.ac.uk

Received: 19-05-2009

Accepted: 07-08-2009 